\title{
MONIKA M. PRZYBYSZ \\ Wpływ kultury organizacji na proces komunikacji z otoczeniem w odniesieniu do instytucji Kościoła rzymskokatolickiego
}

Truizmem byłoby stwierdzenie, że public relations zaczyna się „,w domu”. Przesadą byłoby natomiast zdanie, że wszystko - każdy przejaw działalności organizacji $-\mathrm{z}$ takim samym natężeniem decyduje o jej komunikacji z otoczeniem. Jednak w public relations kultura organizacyjna (zwana często korporacyjną) jest jednym $z$ ważnych narzędzi kształtowania profesjonalnej i skutecznej komunikacji organizacji $\mathrm{z}$ otoczeniem.

System wspólnych pojęć, w znacznym stopniu wyznaczający sposoby postępowania pracowników danej instytucji (tak najkrócej można zdefiniować kulturę organizacji), decyduje w dużym stopniu o „być albo nie być” komunikacyjnym współczesnych instytucji i firm, ponieważ to kultura organizacji decyduje kim one są. To zaś, kim są organizacje, wyznacza kierunek i sposób ich komunikacji.

Podobnie, jak każdy człowiek ma swoją niepowtarzalną i wyjątkową osobowość, zbiór stosunkowo trwałych i stabilnych cech go wyróżniających, tak również organizacje mają swoją unikalną osobowość, swoją kulturę ${ }^{1}$. I podobnie, jak każdy człowiek może komunikować się w różny sposób w zależności od swojej kultury, doświadczenia i umiejętności, tak również organizacja będzie komunikowała siebie, swoje wartości, swoją kulturę komunikacji. Mimo występowania pewnych podobieństw w kulturze organizacji, kultura konkretnej, danej

Monika Marta P R Z Y B Y S Z, dr teologii w zakresie teologii środków społecznego przekazu; adiunkt w Katedrze Prakseologii Dziennikarskiej Wydziału Teologicznego UKSW w Warszawie, wykładowca w Instytucie Politologii UKSW oraz wykładowca WSD Diecezji Warszawskiej, specjalista public relations; e-mail: intellectus@wp.pl

${ }^{1}$ Por. S. P. R obbins, D. A. De Cen zo: Podstawy zarzadzania. Polskie Wydawnictwo Ekonomiczne. Warszawa 2002 s. 250-251. 
organizacji będzie miała zawsze unikalny charakter. Indywidualne wartości, normy, postawy i wspólne cele określają sposób prowadzenia działalności danej instytucji, determinując kształtowanie się jej relacji z otoczeniem. Stąd specyfika kultury organizacyjnej instytucji Kościoła katolickiego będzie wyjątkowa i niepowtarzalna, a jednocześnie bogata rzeczywistość Kościoła jako instytucji będzie traktowana jako rzeczywistość nawiązująca do schematu firmy.

\section{Kultura organizacji}

Na początku najprościej więc będzie określić samo pojęcie kultury organizacji poprzez wyjaśnienie, czym ona nie jest. Zdaniem Horsta Steinmanna i Georga Schreyögga nie jest ona osobliwą architekturą przemysłową, estetycznym wyglądem wyrobów, plastycznym wystrojem budynków lub pięknymi obrazami w biurach $^{2}$. Kultura przedsiębiorstwa to nie urządzanie pretensjonalnych bibliotek fabrycznych lub organizowanie wieczorków poetyckich $w$ fabrycznym centrum szkoleniowym. Nie chodzi też o takie przedsięwzięcia w zakresie gospodarki kadrami, jak kótka jakości lub modele udziału w zysku. Sa to wszystko możliwe części składowe kultury przedsiębiorstwa, ale to w żadnym wypadku nie znaczy, $\dot{z}$ e kultura przedsiębiorstwa musi takie atrybuty posiadać. Takich atrybutów w odniesieniu do Kościoła Katolickiego jednak nie brakuje.

Kultura organizacji nie jest wreszcie również „klimatem”, jaki panuje w organizacji, choć są to pojęcia często mylone, bowiem klimat oznacza atmosferę panującą $\mathrm{w}$ danej jednostce $\mathrm{w}$ bieżącym okresie, a kultura jest czymś o wiele trwalszym, związanym głęboko $\mathrm{z}$ wartościami zakorzenionymi w organizacji. Kultura to rzeczywistość, a klimat to jej postrzeganie ${ }^{4}$.

Kultura organizacji, najkrócej ją definiując, jest po prostu sposobem działania organizacji ${ }^{5}$. Wypływa ona zazwyczaj z misji i wizji założycieli, którzy ustanawiają początkową kulturę, tworząc obraz tego, czym powinna być ich organizacja, bez ograniczeń wcześniejszych zwyczajów i zachowań lub ideologii, bazując na niewielkiej liczbie osób, które początkowo tworzą organizację i w ten sposób dość łatwo narzucając wszystkim pracownikom owe wartości i zasady. Kultura organizacji staje się więc u początku istnienia organizacji wypadkową, wynikiem interakcji, a więc komunikacji, między założeniami i poglądami założy-

\footnotetext{
${ }^{2}$ Por. H. S t e i n m a n n, G. S c h r e y ö g g: Zarzadzanie. Podstawy kierowania przedsiębiorstwem. Koncepcje, funkcje, przyktady. Oficyna Wydawnicza Politechniki Wrocławskiej. Wrocław $1995^{2}$ s. 417.

${ }^{3}$ Por. tamże.

${ }^{4}$ B. F r y z e ł: Kultura korporacyjna. Poglądy, teorie, zarządzani. Wydawnictwo Uniwersytetu Jagiellońskiego. Kraków 2008 s. 77.

${ }_{5}^{5}$ Por. T. L a mbert: Problemy zarzadzania. 50 praktycznych modeli rozwiazań. Dom Wydawniczy ABC. Warszawa 1999 s. 294.
} 
cieli a tym, czego pierwsi pracownicy nauczą się na podstawie własnych doświadczeń, przekazując kolejnym zatrudnianym osobom nie tylko założenia i idee twórców, ale też swoje bogactwo twórczego wkładu ${ }^{6}$. Swoją „osobowość” organizacja zawdzięcza pokoleniom pracowników oraz minionym doświadczeniom, które skłaniają aktualnych zarządców do zachowywania się w pewien sposób, niekiedy bez świadomości, że to robią ${ }^{7}$.

Kulturę organizacja będzie posiadała niezależnie od tego, czy może sobie pozwolić na kształtowanie jej w sposób świadomy, gdy dochody organizacji są wysokie, czy też nie. Pojęcie to nie wskazuje też, jak się wydaje, jedynie na zewnętrzne wpływy kulturowe. Kultura organizacji jest bowiem systemem wzorców i orientacji, które charakteryzują postępowanie członków organizacji wewnątrz i na zewnątrz w sposób trwały ${ }^{8}$. Kultura organizacji wpływa więc w dużym stopniu na sposób zachowania i komunikowania się pracowników zarówno między sobą, a więc $\mathrm{z}$ otoczeniem wewnętrznym, jak i z otoczeniem zewnętrznym. Wartości, symbole, rytuały, mity i praktyki postępowania będą w równym stopniu determinować sposób postrzegania świata przez pracowników i patrzenia nań poprzez okulary wewnętrznej lojalności wobec organizacji ${ }^{9}$. Budowanie jednak tej lojalności nie należy do najłatwiejszych zadań w instytucjach kościelnych, związane jest to bowiem z prozaicznym czynnikiem często zbyt mało konkurencyjnych zarobków w tych instytucjach.

Kultura organizacji jest zespołem podstawowych założeń, które dana jednostka ustanowiła $w$ trakcie pokonywania problemów adaptacji do otoczenia $i$ budowania wewnętrznej integracji ${ }^{10}$. Kultura organizacji powstaje więc jako proces komunikacji otoczenia wewnętrznego, pracowników, zdobywania doświadczenia grupy, ustalania, które z nich są godne zachowania i kontynuacji. To system ludzkich doświadczeń i mądrości, to „,dusza”, „osobowość”, „tożsamość”

\footnotetext{
${ }^{6}$ Por. D. C. H a m b r i c k, S. F in ke l s t e i n: Managerial Discretion: A Bridge over Polar Views of Organizational Outcomes. W: L. L. C u m ming s, B. M. S t a w (red.): Research in Organizational Behavio., JAI Press. Greenwich, CT 1987 s. 384-385.

${ }^{7}$ Por. R. K o c h: Stownik zarządzania i finansów. Narzędzia, terminy, techniki od A do Z. Wydawnictwo Profesjonalnej Szkoły Biznesu. Kraków 1997 s. 120.

${ }^{8}$ Por. H. S t e i n m a n n, G. S c h r e y ö g g: Zarzadzanie. Podstawy kierowania przedsiębiorstwem. Koncepcje, funkcje, przyktady, dz. cyt., s. 417.

${ }^{9}$ Por. A. M. S a p i e $\mathrm{n}$ a: Believing is Seeing: How Culture Influences the Decisions Top Managers Make. W: R. H. K i $1 \mathrm{~m}$ a n n, M. J. S a x t o n, R. S e r p a, (red.): Gaining Control of the Corporate Culture. Jossey-Bass. San Francisco 1985, CA, s. 68; J. H. S herid a n: CultureChange Lessons. „Industry Week”. Vol. 17: 1997 s. 20; L. S m i r c i c h: Concepts of Culture and Organizational Analysis. „Administrative Science Quarterly”. Vol. 28: 1983 nr 3 s. 339-358.

${ }^{10} \mathrm{G}$. G i e r s z e w s k a, B. W a w r z y n i a k: Globalizacja. Wyzwania dla zarzadzania strategicznego. Poltext. Warszawa 2001 s. 159.
} 
organizacji ${ }^{11}$, wyróżniająca go spośród innych organizacji, a więc kształtowana na drodze komunikacji, dialogu.

Istnieją dwa różne podejścia do pojęcia kultura organizacji. W pierwszym wariancie traktowana jest ona jako część całości: kultura jest czymś, co organizacja posiada. W drugim podejściu organizacja jako całość jest uważana za kulturę; to organizacja jest kulturą ${ }^{12}$.

Niezależnie od tych koncepcji, istnieje jednak przynajmniej kilka elementów, łączonych z pojęciem kultury przedsiębiorstwa w obu koncepcjach ${ }^{13}$ : jest ona $\mathrm{w}$ istocie zjawiskiem nieposiadającym oddzielnego bytu, bowiem są to wspólnie podzielane przekonania, które wyciskają piętno na pojmowaniu i identyfikacji własnej organizacji; kultura organizacji jest przeżywana, a oczywiste założenia jej tkwią w codziennej działalności, nie zaś w postaci autorefleksji nad tymi założeniami; poprzez odnoszenie się do wspólnych wartości, przekonań, kultura czyni działalność wszystkich członków, pracowników organizacji jako współgrającą całość, do pewnego stopnia jednolitą i spójną; jest ona efektem uczenia się zarządzania konfliktami i problemami z otoczeniem zewnętrznym i wewnętrznym, a więc posiada swoją historię rozwoju; wyraża ona sposób pojmowania świata przez członków organizacji, przekazuje orientację w złożonym świecie, wprowadzając wzorce dla selekcji i interpretacji programów działania; jest przekazywana w procesie społecznym, nie jest nauczana świadomie.

Na podstawie analizy tych elementów nietrudno zauważyć, że sposób percepcji kultury organizacji przez pracowników związany jest $\mathrm{z}$ wieloma mechanizmami komunikacji, które uzmysławiają nowemu pracownikowi, jak należy działać w rozumieniu kulturowej tradycji, a więc proces uczenia się kultury organizacji jest procesem wpływu otoczenia wewnętrznego na nowo zatrudnionego pracownika.

\section{Kryteria budowania}

Kultura organizacyjna spełnia jednak dwie podstawowe funkcje w organizacji, a mianowicie umożliwia dostosowanie instytucji do otoczenia i zapewnia wewnętrzną integrację tej instytucji ${ }^{14}$. Kultura organizacji jest więc przekazywana i wyrażana, komunikowana. U podstaw kultury leżą zbiory podstawowych

${ }^{11}$ Por. M. R o m a now s k a (red.): Podstawy organizacji i zarzadzania. Difin. Warszawa 2001 s. 120.

${ }^{12}$ Por. Y. A $1 \mathrm{l}$ a i r e, M. E. F i r s i r o t u: Theories of Organizational Culture. „Organization Studies". Vol. 5: 1984 nr 3 s. 193-226.

${ }^{13}$ Por. H. S t e i n m a n n, G. S c h r e y ö g g: Zarzadzanie. Podstawy kierowania przedsiębiorstwem. Koncepcje, funkcje, przyktady, dz. cyt., s. 418-419.

${ }^{14}$ Por. A. K. Koźmińs ki, W. P i ot row ski (red.): Zarzadzanie. Teoria i praktyka. PWN. Warszawa 1995 s. 530. 
wzorców orientacji i wyobrażenia (światopoglądy), kierujące postrzeganiem i działaniem. Chodzi tu o punkty orientacyjne, za którymi podąża się zwykle bezrefleksyjnie, nie zastanawiając się nad tym, najczęściej nie znając ich w ogóle. Punkty te są uporządkowane według pięciu podstawowych problemów ludzkiej egzystencji ${ }^{15}$ : założenia dotyczące otoczenia, pojmowanie prawdy, założenia dotyczące natury człowieka i ludzkiego działania oraz dotyczące stosunków międzyludzkich. Są to niezwykle ważne wyznaczniki budowania kultury organizacyjnej w instytucjach kościelnych.

Sposób, w jaki otoczenie jest postrzegane w organizacji - czy traktowane jest jako zagrożenie czy jako wyzwanie, wpływa na decyzję o wyborze strategii działania. Przykładem może być tu postrzeganie mediów przez niektóre środowiska kościelne jako element wrogi Kościołowi, narzędzie manipulacji. W ten sposób będą traktowani następnie pracownicy mediów, dziennikarzom nie będą udzielane informacje, a udzielenie odpowiedzi do mediów przez księdza może być zależne od deklaracji wstępnej odnośnie do medium, jakie dziennikarz reprezentuje.

Każdy system społeczny tworzy określone wyobrażenia o tym, co stanowi podwalinę, a więc ,instancję prawdy" - tradycja, autorytety, wiedza itp., a wybór ten będzie wpływał na sposób komunikacji w otoczeniu wewnętrznym, jak i zewnętrznym. Także podejście do pracowników będzie determinowało reakcję w stosunku do przełożonych. Nie ma kultury organizacyjnej, która nie dotyczyłaby bowiem reguł współdziałania między pracownikami i dlatego prawidłowo zarządzana komunikacja wewnętrzna może zadecydować o działaniu organizacji, a także wpływać na kształtowanie się kultury organizacji.

Sama również kultura podlega jednak zmianom. David Drennan wskazuje w swoich pracach dwanaście czynników kształtujących kulturę organizacji ${ }^{16}$ : wpływ dominujących liderów, przywódców; historia i tradycja organizacji; technologia, produkty i usługi; klienci; oczekiwania organizacji; systemy informacji i kontroli; ustawodawstwo i otoczenie organizacji; system nagród; organizacja i zasoby; cele, wartości i przekonania. Wśród wymienionych czynników są więc również komunikacja (i to zarówno wewnętrzna, jak i zewnętrzna) oraz otoczenie organizacji. Stąd związek między kulturą organizacji a jej procesem komunikacji z otoczeniem jest ścisły, gdyż z istniejącej kultury organizacji wypływa również sposób kształtowania relacji między organizacją a otoczeniem.

\footnotetext{
${ }^{15}$ Cyt. za: H. S t e i n m a n n, G. S c h r e y ö g g, dz. cyt., s. 420.

${ }^{16}$ Zob. więcej w: D. D re nn a n: Transforming Company Culture: Getting Your Company from Where You are Now, to Where You Want to be. McGraw Hill. London-New York 1992.
} 
Dojrzałość istniejącej kultury organizacji można diagnozować poprzez analizę stopnia występowania $\mathrm{w}$ danej jednostce dziesięciu następujących $\operatorname{cech}^{17}$ : identyfikacji członkowskiej (stopień, w jakim pracownik identyfikuje się bardziej z organizacją jako całością niż z rodzajem wykonywanej pracy lub swoją specjalnością zawodową); akcentowanie grup (stopień, w jakim organizuje się czynności robocze $\mathrm{z}$ większym naciskiem wokół grup niż indywidualnych osób); koncentracja uwagi kadry zarządzającej na ludziach (stopień, w jakim w decyzjach kierowniczych uwzględnia się wpływ ich wyników na ludzi w organizacji); integracja jednostek (stopień, w jakim motywuje się jednostki organizacyjne do działania w sposób zintegrowany lub samodzielny); kontrola (stopień, w jakim wykorzystuje się prawo i nadzór kierowniczy do sprawowania kontroli nad zachowaniami pracowników); tolerancja względem ryzyka (stopień, w jakim pracowników organizacji zachęca się do podejmowania ryzyka, wprowadzania innowacji i postawy agresywnej); kryteria nagradzania (stopień, w jakim nagrody w formie podwyżki płac i awansu są przyznawane na podstawie efektywności pracownika, nie zaś na zasadzie starszeństwa, protekcji i czynników niezwiązanych z efektywnością); tolerancja względem konfliktów (stopień, w jakim zachęca się pracowników do otwartego omawiania konfliktów, wyrażania krytyki i zarządzania konfliktami); nastawienie na środki lub cele (stopień, w jakim kierownictwo skupia uwagę raczej na wynikach niż procesach i technikach zastosowanych do ich uzyskania); skupianie uwagi na otwartości systemu (stopień, w jakim organizacja monitoruje zmiany w otoczeniu i reaguje na nie, a więc działa proaktywnie poprzez zarządzanie problemowe). Należałoby więc przemyśleć kwestię podejmowania wysiłków na rzecz świadomego, nie zaś przypadkowego, budowania kultury korporacyjnej w instytucjach kościelnych.

\section{Rola w życiu organizacji}

Jakie są korzyści z istnienia silnej kultury organizacji? Prowadzi ona do pewnej przewidywalności, porządku, konsekwencji i ładu, bez konieczności stosowania pisemnej dokumentacji, rozporządzeń, przepisów i reguł w sposób formalny ${ }^{18}$, a osoby zarządzające nią nie tracą czasu na ich opracowywanie. $\mathrm{W}$ taki sposób kultura organizacji, kształtując dominujące wartości wspólne, wpływa na strukturę organizacji i jej komunikację wewnętrzną. Zarówno bowiem specjali-

\footnotetext{
${ }^{17}$ Por. między innymi: C. F. Gra y, E. W. La r s o n: Project management: the managerial process. McGraw Hill Professional $2002^{2}$ s. 79; C. A. O' R e i 11 y III, J. C h a t m a n, D. F. Caldwe 11: People and Organizational Culture: A Profile Comparision Approach to Assesing Person-Organization Fit. „Academy of Management Journal”. Vol. 34: 1991 nr 3 s. 487-516; G. $\mathrm{H}$ o f s t e d e, B. N e u i j e n, D. D. O h a y v, G. S a n d e r s: Measuring Organizational Culture: A Qualitative and Quantitative Study across Twenty Case. „Administrative Science Quarterly”. Vol. 35: 1990 nr 2 s 286-316; A. M. P e t t e g r e w: On Studying Organizational Culture. „Administrative Science Quarterly". Vol. 24: 1979 nr 4 s. 570-581.

${ }^{18}$ Por. P. M. S e n g e: Beyond the Bottleneck. „Executive Exellence”. R. 16: 1999 nr 5 s. 20.
} 
zacja pracy (wykonywanie przez poszczególnych pracowników odrębnych fragmentów danego zadania, zamiast całości, a więc praca zespołowa), droga służbowa (zasada zarządzania kadrami, według której każdy pracownik podlega tylko jednemu przełożonemu), rozpiętość kierowania (liczba pracowników, którymi może zarządzać dany kierownik w sposób skuteczny i sprawny), autorytet formalny (uprawnienia kierownika do wydawania poleceń i oczekiwania, że zostaną wykonane) wraz z odpowiedzialnością (zobowiązania do wykonywania przypisanych działań), centralizacja (funkcja stopnia przekazywania uprawnień decyzyjnych na niższe szczeble) wraz z decentralizacją (przekazywanie uprawnień decyzyjnych na najniższe szczeble organizacji) oraz dzielenie czynności w organizacji według funkcji, produktu, klienta, miejsca lub procesu - wszystko to związane jest z kulturą organizacji, zarządzaniem relacjami międzyludzkimi, a także istniejącym stylem komunikacyjnym $\mathrm{w}$ otoczeniu wewnętrznym organizacji ${ }^{19}$.

Istnieje szereg ,pułapek” związanych z zarządzaniem kulturą organizacji, z przeprowadzaniem zmian $\mathrm{w}$ tym zakresie. Wymienia je Tom Lambert ${ }^{20}$ : wprowadzanie zmian w odpowiedzi na najnowsze mody i trendy, nie biorąc pod uwagę realiów działalności gospodarczej; oczekiwania, że powierzchowna zmiana doprowadzi do szybkiego rozwiązania problemów organizacji; kierownictwo niezdolne do ustalenia precyzyjnych celów i poinformowania o nich pracowników i osoby zarządzające; ustalenie celów zbyt licznych lub zbyt sprzecznych; brak zaangażowania wszystkich pracowników w procesie zmiany; niestałość celów lub stałe ich przesuwanie; zmiana kultury oparta na przesłankach ideologicznych; przeciążenie programu zmiany kultury; próba osiągnięcia wielkiej zmiany za jednym razem; sytuacja, w której wartości organizacji nie docierają do wszystkich zainteresowanych; brak zaangażowania ze strony kierownictwa (zmiana jest postrzegana jako coś, co przynosi korzyści jednym z uszczerbkiem dla innych, a więc wymaga komunikacji i zaangażowania); brak monitoringu i nieumiejętność zarządzania procesem zmiany w zależności od wyników; poszukiwanie szybkich rezultatów, zachowania kierownictwa niezgodne z pożądaną kulturą (na przykład w sytuacji kryzysowej, a więc wymaga szczególnego rodzaju komunikacji); przekazywanie uprawnień w sposób przekraczający możliwości pracowników; opór osób zarządzających średniego szczebla lub pracowników (trzeba wyjaśniać potrzebę zmiany, nowe role, uczyć postępowania w nowej kulturze, monitorować i kontrolować aż do osiągnięcia sukcesu); brak zmian struktury, które ułatwiałyby nowe zachowania. Wiedza ta może być przydatna dla instytucji kościelnych.

\footnotetext{
${ }^{19}$ Por. S. P. R o b b i n s, D. A. D e C e n z o: Podstawy zarzadzania, dz. cyt., s. 253.

${ }^{20}$ Por. T. Lambert: Problemy zarzadzania. 50 praktycznych modeli rozwiazań, dz. cyt., s. 307-309.
} 
Kultura organizacji odgrywa ogromną rolę w osiąganiu przez nią sukcesu, jest podstawą przewagi konkurencyjnej, bowiem to właśnie kultura odzwierciedla pewne elementy, które różnią instytucje między sobą, które decydują o tym, że dane przedsiębiorstwo jest rozpoznawalne, identyfikowalne $\mathrm{z}$ określoną ce$\mathrm{chą}^{21}$, w pewien sposób wyjątkowe, jak na przykład firma Volvo z bezpieczeństwem. Ponieważ kultura w organizacji, jak w latach osiemdziesiątych poprzedniego wieku zdefiniował ją Geert Hofstede, jest procesem programowania zachowań członków organizacji, przedstawia wartości, które są ustalone przez wszystkich jej członków, z tymi zasadami powinni utożsamiać się wszyscy pracownicy, postępując zgodnie z nimi przez cały czas. Dlatego kultura organizacji jest właśnie takim elementem, który musi być nieustannie komunikowany, powtarzany, przypominany, uczony; powinna być nad nim w ogóle prowadzona refleksja.

\section{Kultura organizacji sposobem prezentacji tożsamości i płaszczyzną przekazu wartości}

Kultura danego przedsiębiorstwa informuje osoby spoza organizacji o tym, kim ona jest, kształtuje obraz instytucji, często wymagając od pracowników identyfikacji z wartościami danej kultury ${ }^{22}$. Stąd nie jest dziwnym oczekiwanie, by w instytucjach kościelnych pracowały osoby wierzące, praktykujące, żyjące wiarą. To, jakimi wartościami przepojone są firmy japońskie, o których krążą już biznesowe legendy, o rezygnacji przez pracowników tych instytucji nawet $\mathrm{z}$ urlopów wypoczynkowych, by bez wytchnienia służyć swoim pracodawcom, to właśnie świadczy o wartości kultury organizacji jako niezmiernie cennej wartości, cenniejszej nawet, niż cos tak ważnego, jak ludzki odpoczynek. Kultura wpływa więc na otoczenie wewnętrzne organizacji poprzez budowanie zaangażowania pracowników w osiąganie celu (misji, wizji, filozofii, wartości) danej instytucji, w ten sposób zapewniając niewielką rotację pracowników i zwiększając efektywność pracy, a tym samym przyczyniając się do zwiększenia się wydajności i konkurencyjności organizacji, na jej wyniki. Ponadto daje również poczucie zadowolenia klientom oraz pracownikom.

O podstawowych wartościach kultury organizacji, otoczeniu zewnętrznemu i wewnętrznemu określonych informacji dostarcza przede wszystkim sposób współdziałania instytucji z tym otoczeniem, wewnętrzne relacje pomiędzy pracownikami różnego szczebla, a także inne czynniki, nie związane już z otoczeniem. Kultura może być bowiem pojmowana również w wielu aspektach, które instytucja komunikuje otoczeniu, chociażby poprzez odwołania do historii związane z założeniem danej instytucji kościelnej i / lub założycielami, używaną

\footnotetext{
${ }^{21}$ Por. P. B u h 1 e r: Zarzadzanie. One Press. Gliwice 2007 s. 235.

${ }^{22}$ Por. tamże, s. 237.
} 
symbolikę (widoczny aspekt kultury), różne ceremonie i rytuały, żargon, wartości i przekonania.

Najbardziej podstawową typologią kultur stała się koncepcja DealaKennedy'ego ${ }^{23}$, wyłaniająca cztery typy kultur według dwóch cech: wielkości ryzyka i trwałości sprzężenia ${ }^{24}$. Kultura „,wszystko lub nic”, w której rywalizacja jest podstawą istnienia i działania instytucji kształtuje specyficzną kulturę opartą na sukcesie, wyznaczanym przez poważanie, dochód i władzę. Błędy są w tej kulturze mocno piętnowane i trudno mówić w tej kulturze o dobrej komunikacji międzyludzkiej. Kultura ,,igrzysk i chleba” wykazuje silne powiązania z otoczeniem, które jest pełne możliwości, istniejących przyjaznych relacji między pracownikami, eksponowana jest w nim nieskomplikowana współpraca w zespole w komunikacji wewnętrznej, problemy stwarzają głównie klienci. Trzeci rodzaj organizacji to ,analityczna kultura przedsięwzięć”, w której wszystko skoncentrowane jest na podjęciu właściwej decyzji, otoczenie jest traktowane przeważnie jako zagrożenie, poprzez analizy i długookresowe prognozowanie próbuje się nad nim zapanować, przy użyciu naukowo-technicznej racjonalności, ale nawet w tej sytuacji komunikacja z klientami i wewnątrz instytucji jest sformalizowana, uprzejma i nieemocjonalna. Ostatnim modelem jest „kultura procesu”, w której cel ogólny odgrywa rolę podrzędną, współżycie odbywa się drogą porządku hierarchicznego, precyzyjnie określone są najdrobniejsze szczegóły, język jest poprawny i drobiazgowy, panujące ogólnie wzorce orientacji to nieufność i zabezpieczenie się, a najdrobniejszy zabieg jest precyzyjnie dokumentowany.

Patricia Buhler przy pomocy dwóch zmiennych - współżycia społecznego i solidarności - wymienia natomiast nieco inne cztery rodzaje kultur organizacji: sieciową, interesu, podzieloną i społeczną ${ }^{25}$. Sieciowa kultura charakteryzuje się wysokim poziomem współżycia społecznego i niskim poziomem solidarności, kształtując relacje między pracownikami na poziomie życzliwości, przy skupieniu w przedsiębiorstwie bardziej na sprawach społecznych, niż ekonomicznych. Przeciwieństwem jej jest kultura interesu, z wysokim stopniem solidarności i niskim współżycia społecznego, sformalizowanych kontaktach międzypracowniczych, ale dużym stopniem zaangażowania w realizację celów przedsiębiorstwa. W kulturze podzielonej na niskim poziomie są obydwie zmienne, zarówno solidarność, jak i współżycie społeczne, pracownicy nie są zainteresowani osiąganiem celu przedsiębiorstwa, a komunikacja w instytucji jest ograniczona do minimum. Czwartym rodzajem jest kultura społeczna, gdzie dzięki wysokiemu poziomowi współżycia społecznego i solidarności przedsiębiorstwa są przyjazne

\footnotetext{
${ }^{23}$ Zob. więcej w: T. E. D e a l, A. A. K e n n e d y: Corporate cultures. The Rites and Rituals of Organizational Life, Addison-Wesley. Reading, MA 1982.

${ }^{24}$ Omówienie za: H. S t e i n m a n n, G. S c h r e y ög g: Zarzadzanie. Podstawy kierowania przedsiębiorstwem. Koncepcje, funkcje, przyktady, dz. cyt., s. 423-425.

${ }^{25}$ Por. tamże, s. 242.
} 
otoczeniu, a pracownicy zaangażowani i pełni poświęcenia. Komunikacja w organizacji i wobec otoczenia nie tylko jest więc owocem kultury organizacji, ale też wpływa na tę kulturę. Wpływ ten i wzajemna zależność są silne.

Prezentowana typologia Deala-Kennedy'ego oraz Patricii Buhler, bądź inne znane w literaturze typologie (jak choćby Handy'ego, Cooke'a i Lafferty'ego, a także w Polsce Cz. Sikorskiego czy A. Sajkiewicz) są dużym uproszczeniem problematyki kultury organizacji, porządkującym jedynie pewne doświadczenia $\mathrm{z}$ tworzeniem jej i zarządzaniem nią. Jednak zrozumienie kultury przedsiębiorstwa, określenie jej unikalności i próba świadomego jej kształtowania wymaga wysił$\mathrm{ku}$, umiejętności komunikacyjnych i precyzyjnie określonego celu. Typologie te pokazują jednak obrazowo, że wpływ kultury organizacji na komunikowanie się instytucji z otoczeniem jest wzajemnie zależny, bowiem aspekt komunikacyjny jest elementem kształtowania się tej kultury, szczególnie w procesie jej zmian. Zagadnienie to przekracza jednak zakres niniejszej krótkiej analizy wzajemnych relacji między otoczeniem a kulturą organizacji w odniesieniu do instytucji kościelnych i powinno być przedmiotem dalszych analiz. 